\title{
Components that affect the Implementation of Health Services` Strategic Purchasing: A Comprehensive Review of the Literature
}

\author{
Peivand Bastani ${ }^{1}$, Mahnaz Samadbeik ${ }^{2}$, Yalda Kazemifard ${ }^{3}$
}

${ }^{1}$ Ph.D. of Health Services Management, Assistant Professor, Health Human Resources Research Center, Department of Health Service Management, School of Management and Medical Informatics, Shiraz University of Medical Sciences, Shiraz, Iran

${ }^{2}$ Ph.D. of Health Information Management, Assistant Professor, Department of Health Information Technology, School of Allied Medicine, Lorestan University of Medical Sciences, Khorramabad, Iran

${ }^{3}$ M.Sc., Health Human Resources Research Center, School of Management and Medical Informatics, Shiraz University of Medical Sciences, Shiraz, Iran

Type of article: Systematic review

\begin{abstract}
Introduction: Strategic purchasing is one of the mechanisms that can increase access, equity, and efficiency as well as the correct management of health resources. The aim of this study was to extract important and influential factors as necessary infrastructures to implement this method.

Methods: In this comprehensive literature review, 13 databases and search engines were searched from 2000 to 2015 by applying appropriate keywords. From a total of 1403 titles and after ensuring the validity of the study by the Clinical Appraisal Skills Program (CASP) tool, 18 articles that contained title, abstract, and associated text were used in the study, and their related information was analyzed and extracted using an extraction form and LitAssist software.

Results: The findings showed six categories of intervention have been effective in the strategic purchasing of all health interventions in different countries. These six categories were "The target group of users of the service" (demand side), "purchased interventions," "providers and suppliers of interventions" (the supply side), "Methods and incentives" (payment method), "price," and "Structure and organization."

Conclusion: Although the necessity of performing strategic purchasing in the health sector or developing countries is an indisputable fact, it is of great importance to use the experiences of developed countries while considering the factors extracted from the study for implementing this method. In this regard, it is suggested that studies be performed that can lead to assessing the feasibility of strategic purchasing for health services in developing countries and also in Iran to help health policy makers in these countries.
\end{abstract}

Keywords: Health services; Strategic purchasing; Intervention

\section{Introduction}

Health service purchasing is a process in which saved and accumulated money in the financial fund is allocated to service providers (1). In other words, purchasing is a process whereby pooled resources to carry out a series of effective interventions in health promotion is paid to suppliers (2). In addition to the above, purchasing is also referred to financing of the supply sector, which includes a set of arrangements for payment used by buyers of health services to health care providers (3). In this regard, evidence and studies have suggested that resource allocation and purchasing operations have major impacts on cost, access, quality, and customer satisfaction, as well as on the achievement of technical and allocation efficiency resulting from the purchases. These positive impacts have provided a better value for the money that was spent, and this is a way to provide new resources for health care (4,

\section{Corresponding author:}

Assistant Professor Dr. Mahnaz Samadbeik, Department of Health Information Technology, School of Allied Medicine, Lorestan University of Medical Sciences, Khorramabad, Iran.

Tel: +98.6633409971, Fax: +98.6633420030, Email: mahbeik@yahoo.com

Received: January 27, 2016, Accepted: March 28, 2016, Published: May 2016

iThenticate screening: March 27, 2016, English editing: April 04, 2016, Quality control: April 10, 2016

(C) 2016 The Authors. This is an open access article under the terms of the Creative Commons Attribution-NonCommercialNoDerivs License, which permits use and distribution in any medium, provided the original work is properly cited, the use is non-commercial and no modifications or adaptations are made. 
5). For this reason, during health system reforms, attention to the subject of providing resources according to the terms of providing the services and providing health for community through the mechanism of optimal health services purchasing situated on top of the policies. In this regard, the evidence shows that, in some developed countries in the world, efforts to separate and differentiate the functions of accumulation and purchasing and the allocation of resources from one accumulator organization to buyers take place through adjusted capital according to risk to achieve a competitive advantage in purchasing to minimize the problems of competition in the accumulation (6). However, these countries tend to the use purchasing-based models that require that the payment of government, semi-governmental, and third-parties (the insurers) are separated in terms of organization from health services providers (7), and the model of strategic purchasing of health services is one of the best mechanisms that can provide such functionality. According to the definition provided by the World Health Organization (WHO), strategic purchasing is to continually search for ways for making decisions concerning the type, how, and from whom to purchase, since it is desirable to maximize the system's performance (8). In other words, strategic purchasing means interventions that increase systems' responsiveness and enhances financial fitness (9). As evidence of this, the results of Branson's study indicated that about $30 \%$ of Medicare spending as one of the largest buyers of health services in America was unnecessary or expensive to buy services. However, by shifting from traditional purchasing models to strategic purchasing, Medicare and other purchaser institutions will be able to increase access to high quality services and promote justice and patients' satisfaction by using competitive tools. In addition to what is mentioned about management and equitable allocation of resources as the most important strategic purchasing functions, Tangcharoensathien et al. showed that strategic purchasing of health services is one of the key tools of policy to achieve the goals of universal coverage of health, promotion of equitable access, and increasing financial protection. The results of this study showed that strategic purchasing through six operating designed basic service packages, contracts management, establishing a network of service providers as gatekeepers of health, managing monopoly markets, and ensuring their quality, payment management to service providers and the annual budget, avoiding non-cooperative payments, implementing competitive markets, and increasing the purchasing power of buyers of health services can help health systems, especially in developing countries, to achieve the goals of universal health coverage (11).

According to what was said on the benefits and importance of implementing strategic purchasing, it seems that, before everything else, it is necessary to study the full and comprehensive components and factors that affect the implementation of this method for better management and allocation of resources and purchase the most appropriate and most effective health services. This is important even though there differing evidence of increasing efficiency and promoting justice, access, and satisfaction with the establishment of strategic purchasing in the health sector (3$8,10-12)$. Without identifying the important and influential components as necessary infrastructures to implement this method, practically in its performance, much success will not be gained. Therefore, this study aimed to identify the most important components that affect the implementation of the strategic purchasing of health services.

\section{Material and Methods}

The current study was a review study that was performed comprehensively to explain the components that affect the implementation of the strategic purchasing of health services in the world. Research communality included all studies related to the allocation of resources, purchasing, and strategic purchasing in the health sector. For this reason, all studies in the field of purchasing and strategic purchasing of interventions and health services from 2000 (As a baseline for publication of World Health Report on the use of strategic purchasing) were performed by searching for English keywords related to the strategic purchasing of health services in search engines and databases, such as Google, Google Scholar, PubMed, ProQuest, Ebsco, Science Direct, Scopus, and Web of Science and by searching for Persian keywords in Persian databases, such as Magiran, the Scientific Base of Information and Scientific Documentation Center of Iran, the country profile conferences, and Iranmedex. In addition, studies that were conducted in the fields of purchasing and strategic purchasing in non-health areas were excluded due to their lack of compliance with the aims of the study. The instrument used in this study was data extraction forms from previous studies (data collection form). These forms were used in order to preserve the integrity, reduce biases, and increase the reliability and validity of the comprehensive review (13). For this purpose, at first the main list of keywords appropriate to the purpose of research in both English and Persian with the agreement of the research team was selected, and, then, the above databases were searched. A data-collection form based on the retrieved information resources was completed. Table 1 provides the search strategy that was used. 
After searching by using the keywords in the above strategy, 1,403 titles of articles were extracted from the databases and search engines. Then, these titles were entered into Endnote software and unrelated titles were screened. At this stage, 985 relevant titles were identified, and 418 irrelevant titles were excluded. In the next step, the abstracts of the 985 relevant papers were read by three of the researchers with the aim of identifying the most relevant abstracts. In this stage, 123 articles were chosen, and 862 articles were removed. In the final stage, the full texts of the 123 selected articles were investigated. So, the objectives of the articles were considered, and, if appropriate, they were assessed by using the CASP tool with the aim of providing a comprehensive review of the quality of the articles. With this method, 18 articles were approved by the research team, and information in the form of data was recorded. After collecting data from the articles based on the data extraction forms, the findings were integrated and synthesized. Based on these results, the components of the strategic purchasing of health services were identified and classified. We used LitAssist software to organize the research of the literature and to evaluate the results, and we developed comprehensive reviews of the literature.

Table 1. Search strategy of research

Search Engines and Databases: Google, Google Scholar, PubMed, ProQuest, EBSCO,ISI web of science, Scopus, Science Direct, MAGIRAN, Scientific Information Database, Iran doc (2000 to present)

Limits: Language (only resources with at least an abstract in English)

Date: Up to 2015,Jul, 20

Strategy: \#1 AND \#2 AND \#3

\begin{tabular}{|l|l|}
\hline$\# 1$ & Resource allocation OR Resource allocating \\
\hline$\# 2$ & Strategic Purchasing OR Strategic purchase \\
\hline$\# 3$ & Health care OR Medical service OR Medical care OR hospital \\
\hline
\end{tabular}

\section{Results}

The findings from the comprehensive review of the literature in this study showed that a number of components affect strategic implementation and purchasing of health services. Table 2 summarizes these components in the form of six broad categories, including purchased interventions, target group and service users, interventions providers and suppliers, methods and motivations, price and finally, and structure and organization. As follows from Table 2, five studies pointed to the items, such as determining the nature, quality, cost effectiveness, and priority purchased intervention and purchasing policies that were classified in the component group of "purchased interventions," while seven of the 18 examined studies pointed to various items, such as attention to the users of health services, demandside interventions, number of selective interventions for purchasers, demographic, economic, and social indicators of target groups, and also created mechanism of money for patients and the identification of poor and vulnerable groups that were classified in the "group of target and users of service or demand side." Similarly, 13 of the 18 studies pointed out concepts, such as determining the nature of health service providers, choosing the best supplier, attention to distributors and buyers service, attention to competition, independence, freedom and accountability of service providers, efforts to increase the number of the service providers, and choosing the best and most-efficient service provider, which were brought under the general component "providers and suppliers or supply-side interventions." Ten of 18 studies pointed to the factors, such as attention to the incentives to change the behavior of suppliers, financial and performing incentives, encouraging behaviors based on need and application, modify the payment mechanisms, attention to the incentives to improve services, the mechanisms of reducing uncertainty and risk of purchasing health services and collection, aggregation and allocation of resources, use of volume-based contracts, selective, cost-effective and evidence-based and determining purchasing strategies, which were classified in the category of methods and motivations. Also, the results of Table 2 indicate that eight studies pointed to price, payable, real, its competitive and agreements, bargaining power, market rate, the method of subsidy payment, and tariff procedures as components that affect the strategic purchasing of health services, and, finally, six studies emphasized items such as financial and hierarchical structure, environment, laws and regulations, ownership, way of thinking and decision-making, and the management frameworks that were in general category of "Structure and Organization."

\section{Discussion}

In a general summary of the current findings, it seems that six intervention categories: "the target group and the users of services" (demand side), "purchased interventions," "providers and suppliers of interventions" (the supply side), "methods and motives" (payment methods), "price," and "structure and organization" were effective in the strategic purchasing of total health interventions in the different countries. By comparing current findings with the main mentioned models in order to provide strategic purchasing of health services, i.e., the WHO model (8) and the global bank model (14), it seems that the main components that affect the strategic purchasing of health intervention 
in all reviewed studies in the current study, to some extent, are subgroups of WHO's policy levers (what to buy, whom to buy from, whom to buy, how to pay, with what price) (Figure 1). However, according to the World Bank, all of the variables affecting strategic purchasing can be summarized in four general categories, i.e., interventions of demand side (for whom to buy), interventions of supply side (what to buy and from whom to buy), the interventions of price (with what price to buy), and the motivational interventions (how to pay) (Figure 2).

Table 2. Components affecting the implementation of the strategic purchasing of health services

\begin{tabular}{|c|c|}
\hline $\begin{array}{l}\text { The main } \\
\text { component }\end{array}$ & Subcomponent \\
\hline \multirow{5}{*}{$\begin{array}{l}\text { Purchased } \\
\text { interventions }\end{array}$} & Determining the nature of bought interventions \\
\hline & $\begin{array}{l}\text { Determining the priority interventions (high priorities purchase and low priority small } \\
\text { interventions purchase) }\end{array}$ \\
\hline & Determining the shopping policies \\
\hline & Determining the quality of bought interventions \\
\hline & Determining the effectiveness cost of interventions \\
\hline \multirow{6}{*}{$\begin{array}{l}\text { Target groups and } \\
\text { users of services } \\
\text { (demand side) }\end{array}$} & Attention to the users of health service \\
\hline & Attention to the demand side interventions \\
\hline & Attention to the intervention of choice for buyer \\
\hline & Create a mechanism for money following the patient \\
\hline & Attention to the demographic, economic and social indicators of the target group \\
\hline & Identification of poor and vulnerable groups \\
\hline \multirow{7}{*}{$\begin{array}{l}\text { Providers and } \\
\text { suppliers of } \\
\text { interventions } \\
\text { (supply side) }\end{array}$} & Determining the nature of health service providers (private / public) \\
\hline & Attention to industry that the supplier is located in it and choose the best supplier \\
\hline & Attention to the distributor (wholesaler / retailer) \\
\hline & Attention to the service buyers in order to suitable and multiple purchasing (insurances) \\
\hline & Attention to competition, independence, freedom and accountability for service providers \\
\hline & Efforts to increase the number of service providers \\
\hline & Choose the best and most efficient service provider \\
\hline \multirow{10}{*}{$\begin{array}{l}\text { Methods and } \\
\text { incentives (payment } \\
\text { method) }\end{array}$} & Attention to the incentives to change the behavior of suppliers \\
\hline & Attention to financial incentives \\
\hline & Attention to performance incentives and performance-based pay \\
\hline & Encourage behavior based on need and schedule \\
\hline & Modified payment mechanisms (prospective payment mechanisms) \\
\hline & Attention to the incentives to improve services \\
\hline & The use of volume contracts, choice, cost-effective and evidence-based \\
\hline & Attention to the mechanism to reduce uncertainty and the risk of health services purchase \\
\hline & Attention to the mechanisms of collection, aggregation and allocation of resources \\
\hline & Determining the purchasing strategies \\
\hline \multirow[t]{8}{*}{ Price } & Determining the competitive price (highly competitive) \\
\hline & Determining the system of subsidy payment \\
\hline & Attention to the bargaining power \\
\hline & Determining the market rates \\
\hline & Determining the agreed price \\
\hline & Attention to the actual purchase price of health services \\
\hline & Attention to the payable purchase price of health services \\
\hline & Attention to the tariff mechanisms of different interventions \\
\hline \multirow{7}{*}{$\begin{array}{l}\text { Structure and } \\
\text { organization }\end{array}$} & Attention to the financial structure \\
\hline & Attention to the hierarchical structure of the organization \\
\hline & Attention to the ownership of service providers \\
\hline & Attention to the environment and organizational capabilities \\
\hline & Identify laws and regulations \\
\hline & Attention to the thinking and strategic decision making \\
\hline & Attention to the system management framework \\
\hline
\end{tabular}




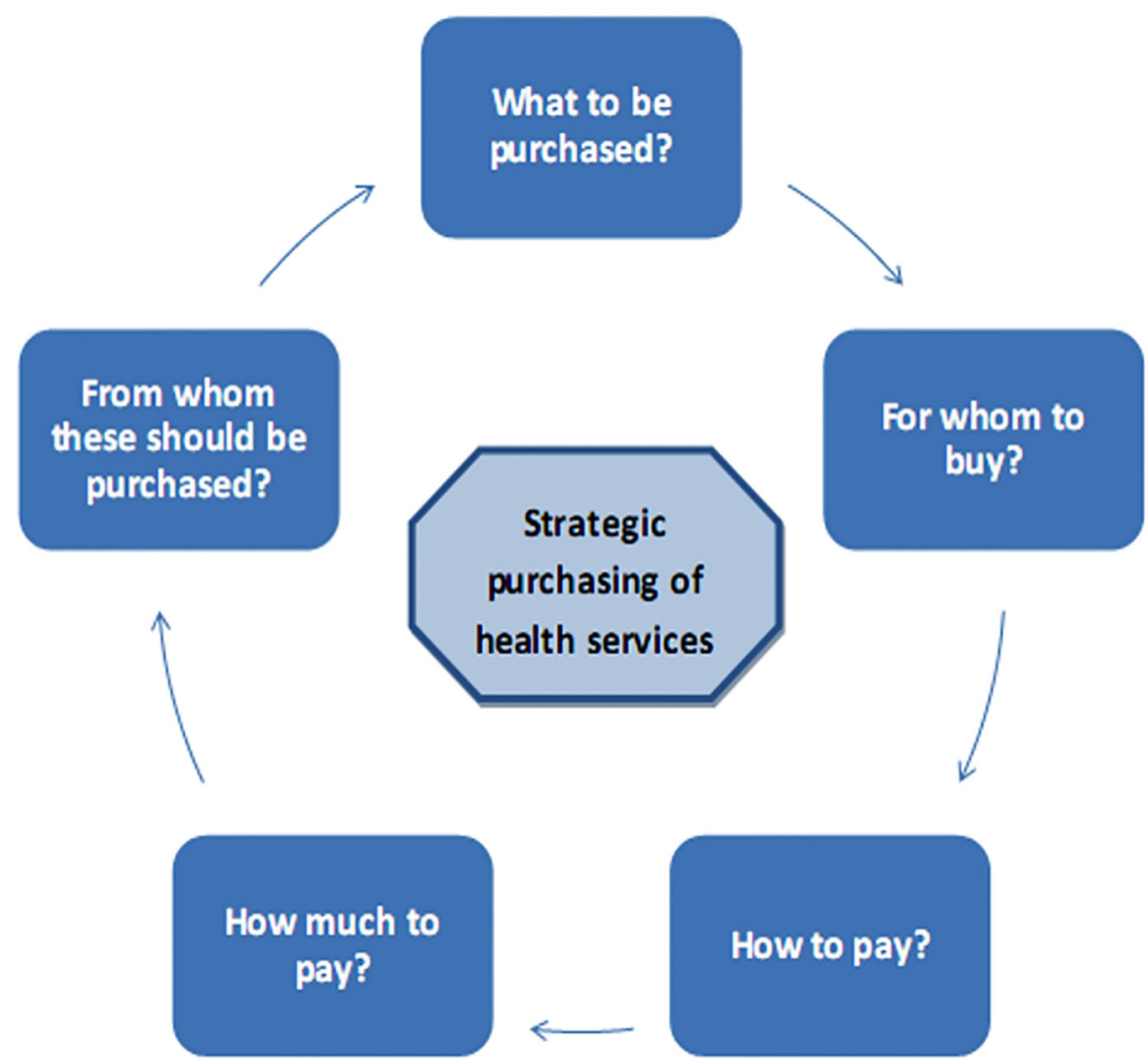

Figure 1. Conceptual model of the strategic purchasing of health services, according to the World Health Organization (8)

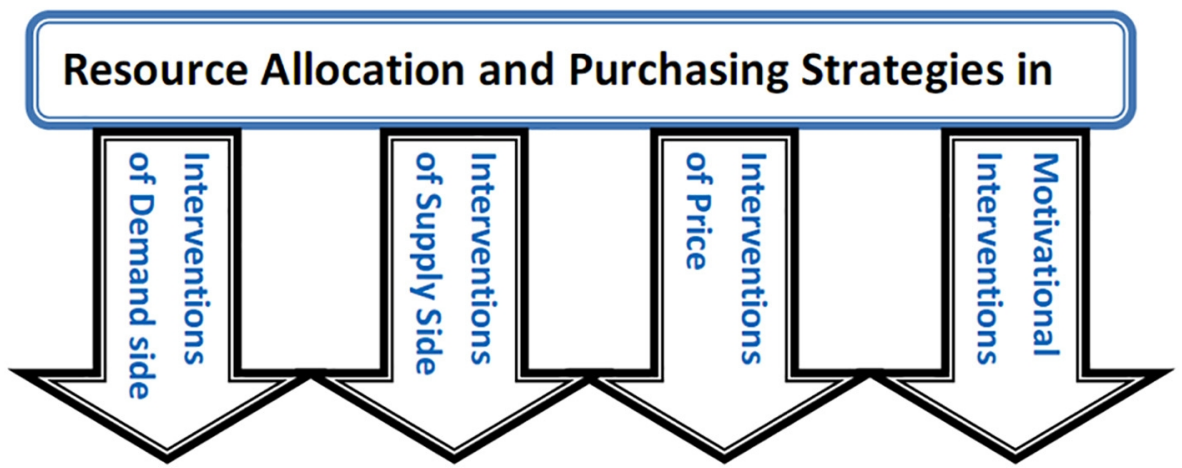

Figure 2. World Bank model for resource allocation and purchasing strategies in health sector (14)

As mentioned above, by comparing two conceptual models and the present findings, it seems that five component categories of purchased interventions, target group, and the users of services (demand side), intervention providers and suppliers (supply side), prices and methods and incentives (payment method) in order what to buy, who to buy, from whom to buy, at what price, and how to deal with is similar to the WHO model. However, about six components of this study (structure and organization), according to the World Bank experts, are not in the strategic purchasing models in other parts of the world, organizational and institutional structures are frameworks that purchase and allocate resources are in those, and, therefore, they were not directly included in the framework of the World Bank (14). However, other studies have shown that purchasing efficiency and allocation of resources depend on the characteristics and responsibilities of making decisions and the level of risk accumulation of resources that 
was placed in the structural and organizational characteristics of purchaser institutions, which will be the executives of strategic purchasing $(15,16)$. In addition, the present review study mostly explained this issue: the ways of implementation of strategic purchasing of health services in different countries were not quite similar and different components affected, for example, evidence from Anear and Bigdeli's study about the way of performing strategic purchasing in Cambodia showed that this country with organizing the Fund resources department of Health (HEF) and by using 4 basic levers of finance, social protection, and ensuring justice, could greatly increase access to health services. Although there is strong political space and support for the full implementation of the strategic purchasing of health services by HEF is required and essential (17). In another under-developed country (Zambia), independence of buyer and supplier and financial resources are the most important factors influencing health services purchasing contract (18).

Evidence from the study of Bastany et al. about the requirements for strategic purchase in Iran suggests that in order to move the process of allocation of resources retrospectively and budget based toward fair allocation and smart purchasing and strategic services should consider strategies to increase access of people to health service, reform the subsidy mechanisms, modified methods of reimbursement, creating a win-win situation to choose the best suppliers and contracts, the culture of rational consumption and induced demand and unnecessary induction reduction (9). In addition, Arni et al.'s study showed that, despite the emphasis of developed countries, such as the United States of America, on the use of agreements and long-term contracts between the buyer institutions and service providers in many African under developing countries the use of such contracts to provide health interventions are not common (19) and perhaps this is one reason that despite the emphasis of the World Health Organization and the World Bank to implement the strategic purchasing of health services as a means of improving access, equity and efficiency in developing countries, this is still unrealized in many countries, including Iran. In addition, the legal capacity and strengthen the technical infrastructure for the development and management of long-term contracts with improvement of appropriate service delivery and cost-effective help the facilitation of the use of the strategy purchase contracts in developing countries.

\section{Conclusions}

In a general summary of what was said it seems that although the necessity of implementation of strategic purchasing in the health part for developing countries is an indisputable fact, but in the meantime using the experiences of developed countries while considering the creation of the necessary infrastructures to implement this method is of utmost importance. In addition, the use of the results of this study and similar articles can also determine the prerequisites and requirements for the establishment of strategic purchasing of health services along with comprehensive information about its benefits and achievements. In this regard, it is suggested to perform studies that lead to feasibility strategic purchasing of health services in developing countries including Iran to help health policy makers in these countries.

\section{Acknowledgments:}

This study was part of a Ph.D. dissertation supported by Iran University of Medical Sciences, grant No: $43 / 1392$. The authors declare that there is no conflict of interest.

\section{Conflict of Interest:}

There is no conflict of interest to be declared.

\section{Authors' contributions:}

All authors contributed to this project and article equally. All authors read and approved the final manuscript.

\section{References}

1) Anderson GF, Hussey P. Special Issues With Single-Payer Health Insurance Systems. World Bank Health, Nutrition and Population (HNP) Discussion Paper, 2004

2) Hasan Zadeh Khakmardani A. Determining a Model for Strategic purchasing of outpatient health care services, World Health Organization, Final Report APW: 07/38, Dec 2007

3) MehralianGh, Bastani P. Pharmaceutical strategic purchasing: a key to improve access to medicines. Iran J Pharm Res. 2015;14(2):345-6. PMID: 25901141. PMCid: PMC4403050 
4) Ramezanian M, Abolhalaj M, BastaniP, Fazl Hashemi SE, Hamidi H. Islamic Republic of Iran Health System Financing:Weak and Strength Points with a Qualitative Attitude. World J. Med. Sci, 2013; (3): 231 37. DOI: 10.5829 /idosi.wjms.2013.8.3.73163

5) McSorley G. Strategic purchasing: the experience in England. Healthc pap, 2007;8(SP):77-92. PMID: 19096268

6) Steinle C, Schiele H. Limits to global sourcing? Strategic consequences of dependency on international suppliers: cluster theory, resource based view and case studies. J Purchase Supply Manage, 2008;14(1):314. DOI: 10.1016/j.pursup.2008.01.001

7) Ibrahimipour H, Maleki MR, Brown R, Gohari MR, Karimi R, DehnaviehR. A qualitative study of the difficulties in reaching sustainable universal health insurance coverage in Iran. Health Policy Plan, 2011;26:485-495. PMID: 21303879

8) WHO The World Health Report 2000.Health systems: improving performance. Geneva, World Health Organization, 2000

9) Bastani P, Mehralian G, Dinarvand R. Resource allocation and purchasing arrangements to improve accessibility of medicines: Evidence from Iran. J Res pharm Pract. 2015; 4 (1): 9-17. DOI: 10.4103/2279042X.150045; PMID: 25710045

10) Bernson RA. Getting serious about executive medicare spending: a purchasing model. Health Aff, 2003:586-602. PMID: 15506162

11) Tangcharoensathien V, Limwattananon S, Patcharanarumol W, Thammatacharee J, JongudomsuP, Sirilak S. Achieving universal health coverage goals in Thailand: the vital role of strategic purchasing. Health Policy Plan,2014;29(5):1-10. DOI: 10.1093/heapol/czu120; PMID: 25378527

12) Bastani P, Dinarvand R, Samadbeik M, Pourmohammadi K. Pharmaceutical strategic purchasing requirements in Iran: Price interventions and the related effective factors. J Res Pharm Pract. 2016;5(1):35. DOI: $10.4103 / 2279-042 X .176553$

13) Sajjadi HS, Seyedin, H, Aryankhesal A, Sarabi Asiabar A. A Systematic Review on the Effectiveness of Thermography in Diagnosis of Diseases. Int Imag Syst and Tech, 2013; 23(2):188-93. DOI: 10.1002/ima.22051

14) Preker AS, Langenbrunner JC. Spending wisely. Buying Health Services for the Poor, The International Bank for Reconstruction and Development / The World Bank Washington, D.C., 2005.

15) Strategic framework for equity funds: promoting access to priority health services among the poor. Phnom Penh: Ministry of Health, Government of Cambodia; 2003.

16) Preker AS, Baeza C, Jakab M, Langenbrunner J. Resource allocation and purchasing (RAP): arrangements that benefit the poor and excluded groups, World Bank, 2000.

17) Ahmadi M, Samadbeik M, Sadoughi F. Modeling of outpatient prescribing process in iran: a gateway toward electronic prescribing system. Iranian journal of pharmaceutical research: Iran J Pharm Res. 2014;13(2):725. PMID: 25237369

18) Bigdeli M, Annear PL. Barriers to access and the purchasing function of health equity funds: lessons from Cambodia. Bull World Health Organ, 2009;87:560-4. DOI: 10.2471/BLT.08.053058

19) Mundenda D, Mapoma C, Chita B, Vhompolola A, Wake W. Provider purchasing and contracting for health services: the case of Zambia. University of Zambia Economics Department, 2008:69-71.

20) Arney L, Yadav P, Miller R, Wilkerson T. Strategic contracting practices to improve procurement of health commodities. Glob Health Sci Pract, 2014;2(3): 295- 306. doi: 10.9745/GHSP-D-14-00068

21) Preker AS, Langenbrunner JC, Belli PC. Public Ends Private Means Strategic Purchasing of Health Services. 1st ed. Washington DC: The World Bank Publisher; 2007:11-25. DOI: 10.1596/978-0-8213$6547-2$ 